\title{
Prevalence and Sociodemographic Factors of Overweight and Obesity among Pakistani Adults
}

\author{
Muhammad Asif ${ }^{1, *}$, Muhammad Aslam², Saima Altaf' ${ }^{2}$, Saima Atif ${ }^{3}$, Abdul Majid ${ }^{4}$ \\ ${ }^{1}$ Department of Statistics, Government Degree College, Qadir Pur Raan, Multan; ${ }^{2}$ Department of Statistics, Bahauddin Zakariya University, Multan; ${ }^{3}$ Department of \\ Statistics, University of Sialkot, Sialkot; ${ }^{4}$ Pakistan Bureau of Statistics, Regional Office Multan, Multan, Pakistan
}

Background: Obesity is a serious public health problem that is growing alarmingly worldwide. The main objective of this study is to examine the current prevalence of overweight and obesity among Pakistani adults and to identify the sociodemographic factors that are associated with overweight and obesity.

Methods: Secondary data from a population-based household survey (the Pakistan Panel Household Survey) were used for this study. A total of 10,063 participants (3,916 men and 6,147 women) were included. Overweight and obese individuals were identified using the World Health Organization-recommended cutoffs for body mass index $\left(\mathrm{kg} / \mathrm{m}^{2}\right)$. Along with descriptive statistics, the Pearson chi-square test was used to investigate the association among categorical variables. Odds ratios (ORs) along with $95 \%$ confidence intervals (Cls) were estimated using univariate logistic regression analysis to evaluate the most significantly associated risk factors for overweight/obesity.

Results: The mean age and body mass index of the participants were 38.2 years and $22.9 \mathrm{~kg} / \mathrm{m}^{2}$, respectively. Overall, $22.8 \%$ of the participants ( $23.9 \%$ of the women and $21.1 \%$ of the men) were overweight, and $5.1 \%$ (6.3\% of the women and $3.2 \%$ of the men) were obese. Sociodemographic factors, such as sex, marital status, and residential area, were significantly associated with body mass index categories. Women $(\mathrm{OR}, 1.34 ; 95 \% \mathrm{Cl}$, 1.23-1.47; $P<0.01)$, ever-married individuals $(\mathrm{OR}, 1.92 ; 95 \% \mathrm{Cl}, 1.70-2.16 ; P<0.01)$, and individuals living in urban areas $(\mathrm{OR}, 1.23 ; 95 \% \mathrm{Cl}, 1.12-1.35 ; P<0.01)$ were more likely to become overweight/obese than their counterparts.

Conclusion: We have found the excess weight problem to be quite high in the Pakistani adult population. The government and other health agencies should take initiatives in launching programs about nutritional awareness for adults to prevent obesity.

Key words: Body mass index, Overweight, Obesity, Pakistani adults, Pakistan Panel Household Survey

Received July 18, 2019

Reviewed August 25, 2019

Accepted November 18, 2019

${ }^{*}$ Corresponding author

Muhammad Asif

(i)

https://orcid.org/0000-0002-4406-7755

Department of Statistics, Government Degree College, Oadir Pur Raan, Multan 60000, Pakistan

Tel: +92-332-6038247

Fax: +92-304-7928081

E-mail: asifmalik722@gmail.com

\section{INTRODUCTION}

Over the last few decades, evidence has strongly suggested that overweight and obesity have increased at worrying levels globally. ${ }^{1}$ Between 1980 and 2014, the obesity burden among adults grew to more than double. The prevalence of overweight and obesity is higher in women than in men., Due to the large prevalence, the World Health Organization (WHO) declared overweight and obe- sity as a global epidemic., At present, almost every nation is experiencing this situation, although to significantly varying degrees not only by nation and region, but also by race and ethnic group. ${ }^{3,4}$

Many developing countries such as Pakistan have been facing a dual challenge of having both underweight and excess body weight populations. Having excess body weight was once perceived to be a phenomenon of the developed world. However, in recent years, it has extended to developing countries. Now, the burden of over-

Copyright (C) 2020 Korean Society for the Study of Obesity

(a) This is an Open Access article distributed under the terms of the Creative Commons Attribution Non-Commercial License (http://creativecommons.org/licenses/by-nc/4.0/) which permits unrestricted non-commercial use, distribution, and reproduction in any medium, provided the original work is properly cited. 
weight and obesity in developing countries, including Pakistan, has increased several-fold. In 2014, global disease estimates showed that Pakistan stands at number eight among the 10 countries hosting half of the 693 million obese individuals in the world. ${ }^{5}$

Body mass index (BMI), calculated as weight in kilograms divided by height in squared meters, has long been the accepted criterion used for body weight assessment of an individual. Usually, BMI cutoffs of $25.0-29.99 \mathrm{~kg} / \mathrm{m}^{2}$ and $\geq 30.0 \mathrm{~kg} / \mathrm{m}^{2}$ are used for classifying overweight and obese, respectively. ${ }^{3}$ Globally, various noncommunicable diseases (i.e., cardiovascular diseases, hypertension, type 2 diabetes mellitus, dyslipidemia, cancer) are associated with larger BMI, and a major share of these diseases are from developing countries. ${ }^{6}$

When considering the severe health hazards associated with overweight and obesity, it becomes necessary to study this health problem for a particular population. Various population-based epidemiological studies ${ }^{7-10}$ have been conducted on exposing the obesity issue in adults as a public health concern. However, in Pakistan, limited data exist showing the nationwide prevalence of obesity among adults. For instance, Jafar et al. ${ }^{11}$ used the data from National Health Survey of Pakistan (NHSP; 1990-1994) and reported that $25.0 \%$ of adults were either overweight or obese. These estimates based on NHSP data are now out-of-date and need to be recomputed. Moreover, massive changes in dietary intake patterns and an increasingly sedentary lifestyle distinguish normal weight adults from those that are overweight or obese. This fact also suggests that the overweight and obesity estimates of adults should be updated. We therefore designed the present work. The main objective of the study is to examine the current prevalence of overweight and obesity in the adult population of Pakistan. We also identify the potential sociodemographic factors that are associated with overweight and obesity.

\section{METHODS}

\section{Design, setting, and study population}

Data from the Pakistan Panel Household Survey (PPHS-2010) were used for the attainment of this study's objective. The PPHS was conducted as a joint project between the Pakistan Institute of Development Economics, Islamabad and World Bank to analyze poverty and social dynamics in Pakistan. In this multidimensional household survey, health-related information such as height and weight are available for both sexes and for every age group to complete a nutritional status assessment of the Pakistani population. However, only the data for adults (age 19 years or over) are of concern in this study.

This population-based household survey was conducted in 16 different districts of four major administrative units, or provinces, namely: Punjab, Sindh, Khyber Pakhtunkhwa, and Balochistan (Fig. 1). Further details about the sample size, sampling procedure, and design can be seen from an earlier report by Durr-e-Nayab and Arif. ${ }^{12}$ Here, however, we highlight some of the methods relevant to the current study.

Out of a total of 29,744 individuals surveyed, 10,063 adults were included in the present analysis. Missing observations (where height or weight were not available) and outliers (using box plots) were already excluded. Among the total study population $(n=10,063)$, 3,755 individuals belonged to six districts of Punjab (Faisalabad $[\mathrm{n}=899]$, Attock [ $\mathrm{n}=464]$, Hafizabad $[\mathrm{n}=607]$, Vehari $[\mathrm{n}=527]$, Muzaffargarh [n=517], and Bahawalpur $[\mathrm{n}=741]) ; 3,603$ were from four districts of Sindh (Badin $[\mathrm{n}=1,558]$, Nawab Shah $[\mathrm{n}=$ 878], Mirpur Khas [n=521], and Larkana [n=646]); 1,485 were

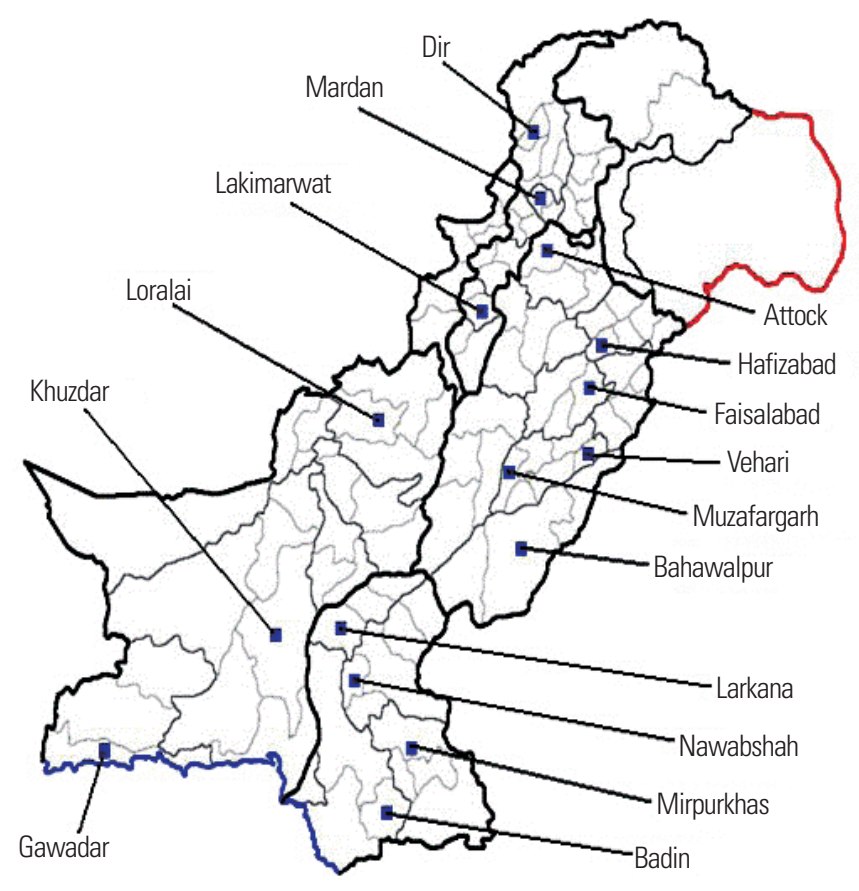

Figure 1. Selected districts for the Pakistan Panel Household Survey (PPHS-2010). 
from three districts of Khyber Pakhtunkhwa (Dir [n=826], Mardan [ $\mathrm{n}=479]$, and Lakki Marwat [ $=180])$; and 1,220 were from three districts of Balochistan (Loralai [ $\mathrm{n}=374]$, Khuzdar $[\mathrm{n}=411]$, and Gwadar $[\mathrm{n}=435])$.

\section{Ethical approval}

The study was approved by the Departmental Ethics Committee of Bahauddin Zakariya University, Multan, Pakistan (IRB No. SOC/D/2511/19). Informed consent was waived because researchers only accessed and analyzed the secondary data set. The authors assert that all procedures contributing to this work complied with the ethical standards of the relevant national and institutional committees on human experimentation and with the Helsinki Declaration of 1975, as revised in 2008.

\section{Data collection}

Data on demographics (age, sex, marital status, area of residence) and health-related variables (height $[\mathrm{cm}]$ and weight $[\mathrm{kg}]$ ) were obtained from the above stated source. For the individual's nutritional status assessment, the international cutoffs recommended by WHO were used in the study. These classifications of nutritional status assessment are as follows: BMI $<18.5 \mathrm{~kg} / \mathrm{m}^{2}$, underweight; $18.5 \leq \mathrm{BMI}<25.0 \mathrm{~kg} / \mathrm{m}^{2}$, normal weight; $25.0 \leq \mathrm{BMI}<30.0 \mathrm{~kg} / \mathrm{m}^{2}$, overweight; and BMI $\geq 30.0 \mathrm{~kg} / \mathrm{m}^{2}$, obese. ${ }^{2,3}$

\section{Statistical analysis}

For primary statistical analysis, the prevalence of overweight and obesity were determined according to age, sex, marital status, and area. Some descriptive statistics (i.e., mean, standard deviation [SD], and centile values) of each quantitative variable were presented by sex and age group. sex-wise mean difference was tested using the two-sample t-test. The analysis of variance technique was used to identify any mean difference between the age groups in both men and women. Meanwhile, the Pearson chi-square test was used to determine the association between categorical variables. Furthermore, using univariate logistic regression, odds ratios (ORs) and their corresponding 95\% confidence intervals (CIs) were estimated to evaluate the most important factors associated with overweight/obesity. For the logistic regression analysis, overweight including obesity $\left(\mathrm{BMI} \geq 25.0 \mathrm{~kg} / \mathrm{m}^{2}\right)$ and obesity (BMI $\geq 30.0 \mathrm{~kg} / \mathrm{m}^{2}$ ) were used as the dependent variables (i.e., overweight $/$ obesity $=1$ with normal weight $=0$ and obesity $=1$ with normal weight $=0$, respectively). All statistical analyses were performed using IBM SPSS version 21.0 (IBM Corp., Armonk, NY, USA), and a $P$-value $<0.05$ was considered as statistically significant in our analysis.

\section{RESULTS}

A total of 10,063 participants (38.9\% men and $61.1 \%$ women) were included in this study. The mean (SD) age of the participants was 38.20 years (15.67 years). More than two-thirds of the participants (68.8\%) were young adults (i.e., 19-44 years of age), and a majority of the participants (71.9\%) were married. The ratio of rural to urban residence was $2.68: 1$, where $72.8 \%$ were rural residents and $27.2 \%$ were urban. Compared to the urban participants, the rural participants were more likely to be older and married. Of the total of 10,063 participants, 2,296 (22.8\%) were overweight, and 512 (5.1\%) were obese (Table 1), and the mean (SD) BMI was

Table 1. Distribution of sociodemographic and nutrition-related characteristics of the study population $(n=10,063)$

\begin{tabular}{lc}
\hline Characteristics & Value \\
\hline Age group (yr) & $38.20 \pm 15.67$ \\
$19-34$ & $5,029(50.0)$ \\
$35-44$ & $1,892(18.8)$ \\
$45-54$ & $1,410(14.0)$ \\
$55-64$ & $932(9.3)$ \\
$\geq 65$ & $800(7.9)$ \\
Sex & \\
Men & $3,916(38.9)$ \\
Women & $6,147(61.1)$ \\
Marital status & \\
Married/living with partner & $7,236(71.9)$ \\
Divorced $/$ separated $/$ widower & $732(7.3)$ \\
Unmarried & $2,095(20.8)$ \\
Area of residence & \\
Rural & $7,329(72.8)$ \\
Urban & $2,734(27.2)$ \\
Nutritional status & $22.91 \pm 3.89$ \\
Underweight $\left(\mathrm{BMl}<18.5 \mathrm{~kg} / \mathrm{m}^{2}\right)$ & $1,284(12.8)$ \\
Normal weight $\left(18.5 \leq \mathrm{BMl}<25.0 \mathrm{~kg} / \mathrm{m}^{2}\right)$ & $5,971(59.3)$ \\
Overweight $\left(25.0 \leq \mathrm{BMl}<30.0 \mathrm{~kg} / \mathrm{m}^{2}\right)$ & $2,296(22.8)$ \\
Obese (BMl $\left.\geq 30.0 \mathrm{~kg} / \mathrm{m}^{2}\right)$ & $512(5.1)$ \\
\hline
\end{tabular}

Values are presented as mean \pm standard deviation or number $(\%)$. $\mathrm{BMl}$, body mass index. 

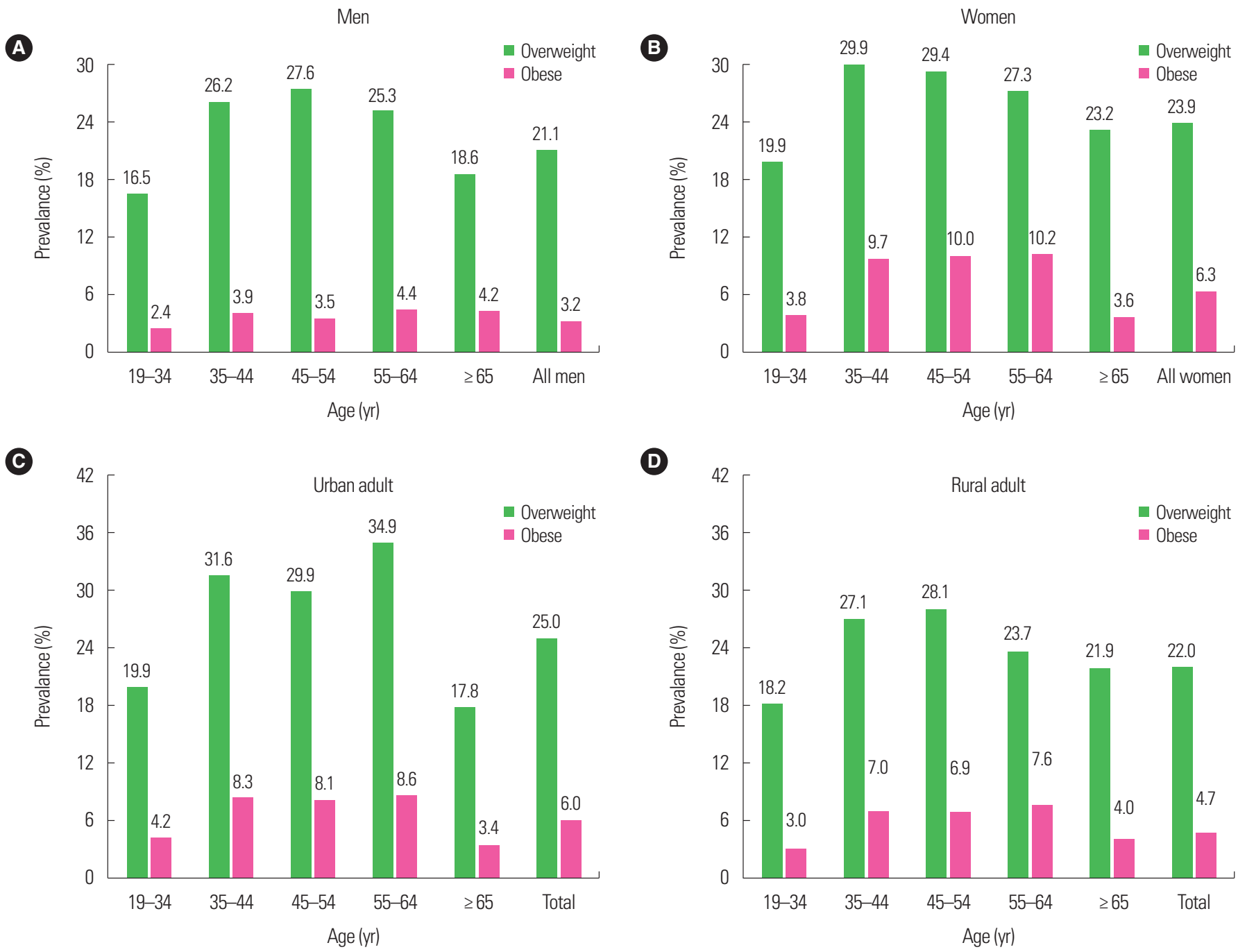

Figure 2. Age-wise prevalence of overweight and obesity in both men (A) and women (B) and in urban (C) and rural (D) adults.

$22.91 \mathrm{~kg} / \mathrm{m}^{2}\left(3.89 \mathrm{~kg} / \mathrm{m}^{2}\right)$. Using a BMI of $25 \mathrm{~kg} / \mathrm{m}^{2}$ as the cutpoint, the prevalence of overweight or obesity differed across sex (women vs. men, $30.2 \%$ vs. $24.3 \%$ ), area (urban vs. rural, $31.0 \%$ vs. $26.7 \%$ ), and marital status (ever-married vs. unmarried, $30.4 \%$ vs. 18.5\%) (Figs. 2, 3). After applying the chi-square test, age and all previously-mentioned categorical variables were significantly $(P<0.001)$ associated with the nutritional status categories of Pakistani adults.

Among both men and women, age-specific obesity prevalence increased until age 64 and declined thereafter. The obesity problem peaked for both women (10.2\%) and men (4.4\%) in the 55-64 age group. However, overweight prevalence was highest for women (29.9\%) in the 35-44 age group, compared to being highest for men (27.6\%) in the 45-54 age group (Fig. 2). Age-specific obesity trends according to residential area show that urban adults aged 55-64 years had a higher obesity prevalence than their rural counterparts ( $8.6 \%$ vs. $7.6 \%$, respectively). For the other age-groups (except those 65 or older), overweight and obesity prevalence in urban residents were also higher than in rural residents (Fig. 2). The difference in percentage points indicates that the obesity threat is more serious in urban adults than in rural ones.

Sex- and age-specific descriptive measures (means, SD, and centiles) of BMI are presented in Table 2. The results reveal that women have significantly $(P<0.01)$ higher mean BMI than men for each age-group as well as in the overall sample (i.e., women vs. men, $23.04 \pm 4.09$ vs. $22.70 \pm 3.54 \mathrm{~kg} / \mathrm{m}^{2}$, respectively). It was ob- 
(A)

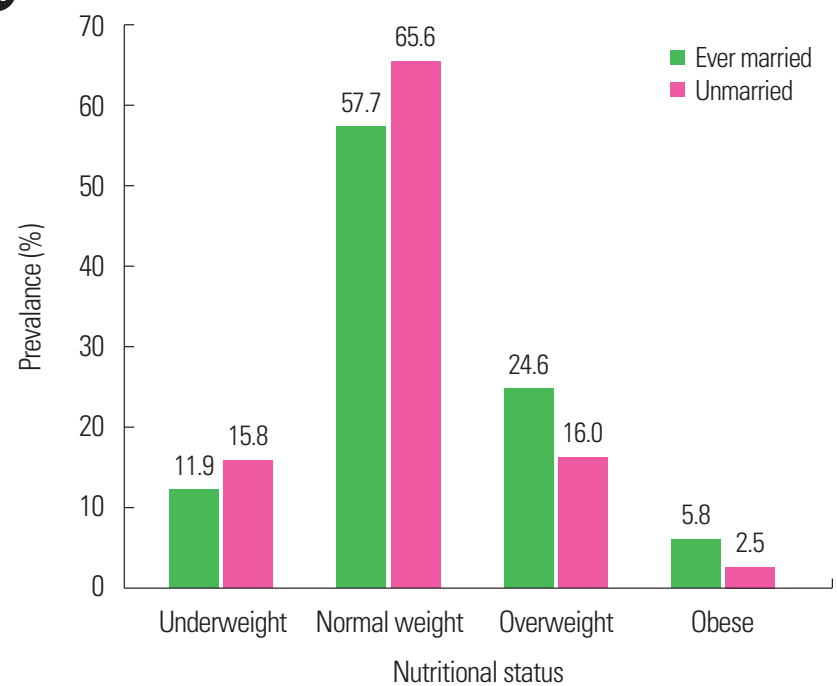

B

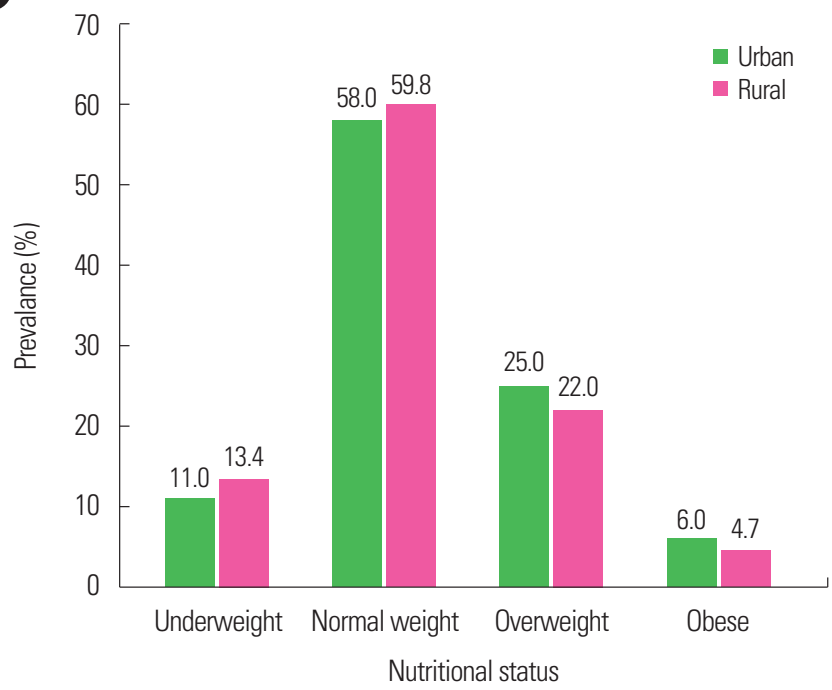

Figure 3. Distribution of nutritional status of Pakistani adults by marital status (A) and residential area (B). Ever married includes married/living with partner and divorced/ separated/widower.

Table 2. Descriptive measures of BMl among Pakistani adults

\begin{tabular}{|c|c|c|c|c|c|c|c|c|c|c|}
\hline \multirow{2}{*}{ Characteristics } & \multirow{2}{*}{ Age (yr) } & \multirow{2}{*}{ Mean $\pm S D$} & \multicolumn{8}{|c|}{ Percentile } \\
\hline & & & 5 & 10 & 25 & 50 & 75 & 85 & 90 & 95 \\
\hline \multirow[t]{6}{*}{$\mathrm{BMI}\left(\mathrm{kg} / \mathrm{m}^{2}\right)^{*}$} & $19-34$ & $22.15 \pm 3.40$ & 17.23 & 18.13 & 19.72 & 21.80 & 24.13 & 25.78 & 27.05 & 28.62 \\
\hline & $35-44$ & $23.41 \pm 3.44$ & 17.92 & 19.04 & 21.22 & 23.23 & 25.44 & 27.32 & 28.06 & 29.49 \\
\hline & $45-54$ & $23.43 \pm 3.47$ & 17.87 & 19.03 & 21.09 & 23.42 & 25.65 & 27.34 & 28.13 & 29.44 \\
\hline & $55-64$ & $23.15 \pm 3.73$ & 16.84 & 18.02 & 20.72 & 23.31 & 25.40 & 27.02 & 28.22 & 29.90 \\
\hline & $\geq 65$ & $22.36 \pm 3.80$ & 16.17 & 17.63 & 19.59 & 22.22 & 24.80 & 26.29 & 27.34 & 29.37 \\
\hline & All men & $22.70 \pm 3.54$ & 17.30 & 18.37 & 20.27 & 22.49 & 24.90 & 26.56 & 27.52 & 29.30 \\
\hline \multirow[t]{6}{*}{ BMI $\left(\mathrm{kg} / \mathrm{m}^{2}\right)^{*, \dagger}$} & $19-34$ & $22.36 \pm 3.82$ & 16.63 & 17.59 & 19.63 & 22.21 & 24.89 & 26.48 & 27.55 & 29.34 \\
\hline & $35-44$ & $23.97 \pm 4.17$ & 17.06 & 18.59 & 21.08 & 23.74 & 26.83 & 28.89 & 29.90 & 31.25 \\
\hline & $45-54$ & $24.07 \pm 4.18$ & 16.97 & 18.30 & 21.12 & 23.74 & 27.27 & 28.97 & 30.01 & 31.19 \\
\hline & $55-64$ & $23.90 \pm 4.30$ & 16.88 & 18.17 & 21.11 & 23.47 & 26.73 & 28.91 & 30.08 & 31.25 \\
\hline & $\geq 65$ & $22.52 \pm 4.12$ & 15.76 & 17.05 & 19.37 & 22.51 & 25.30 & 26.99 & 28.31 & 29.59 \\
\hline & All women & $23.04 \pm 4.09$ & 16.65 & 17.78 & 20.03 & 22.79 & 25.78 & 27.56 & 28.90 & 30.45 \\
\hline
\end{tabular}

${ }^{*}$ Significant mean difference between age ranges in both men and women $(P<0.01)$, analysis of variance; ${ }^{~}$ Significant mean difference between men and women $(P<0.01)$, t-test. BMI, body mass index; SD, standard deviation.

served that the percentile values of BMI, including the median (50th) and lower percentiles, increased for the age group of 45-54 years among both sexes, while higher percentiles $\left(\mathrm{P}_{75}, \mathrm{P}_{90}\right.$, and $\left.\mathrm{P}_{95}\right)$ increased for the ages of 55-64 years and declined afterwards. The 95th BMI percentile values for women across multiple age-groups indicate that a higher proportion of Pakistani adult women fell in the category of obesity compared to men.

Estimated crude ORs, along with their 95\% CI, representing the risks of being overweight and obese or exclusively obese are presented in Table 3. The results, which were derived from a logistic regression model, revealed that the risk of getting excess weight (i.e., BMI $\left.\geq 25.0 \mathrm{~kg} / \mathrm{m}^{2}\right)$ increased until the age of 64 and decreased thereafter. Female participants were more at risk of excess weight (OR, 1.34; 95\% CI, 1.23-1.47) than males. Moreover, ever-married (OR, 1.92; 95\% CI, 1.70-2.16) and urban residential (OR, 1.23 ; $95 \% \mathrm{CI}, 1.12-1.35$ ) participants were also more likely to be overweight or obese as compared to unmarried and rural participants, respectively. Crude ORs for the risk of reaching obese status (i.e., BMI $\geq 30.0 \mathrm{~kg} / \mathrm{m}^{2}$ ) showed that the risk was significantly higher in middle-aged adults (i.e., 35-64 years), women, ever-mar- 
Table 3. Estimated crude ORs demonstrating the risk of overweight and obesity $\left(\mathrm{BMl} \geq 25.0 \mathrm{~kg} / \mathrm{m}^{2}\right)$ and obesity alone $\left(\mathrm{BMl} \geq 30.0 \mathrm{~kg} / \mathrm{m}^{2}\right)$ in Pakistani adults

\begin{tabular}{lll}
\hline \multirow{2}{*}{ Characteristics } & \multicolumn{2}{c}{ Crude OR (95\% Cl) } \\
\cline { 2 - 3 } & \multicolumn{1}{c}{$\mathrm{BMI} \geq 25.0 \mathrm{~kg} / \mathrm{m}^{2}$} & $\mathrm{BMI} \geq 30.0 \mathrm{~kg} / \mathrm{m}^{2}$ \\
\hline Age (yr) & 1.0 & 1.0 \\
$19-34$ & $1.98(1.77-2.23)$ & $2.34(1.86-2.95)$ \\
$35-44$ & $1.99(1.75-2.26)$ & $2.28(1.77-2.94)$ \\
$45-54$ & $1.86(1.60-2.16)$ & $2.49(1.87-3.31)$ \\
$55-64$ & $1.18(0.99-1.40)$ & $1.18(0.80-1.75)$ \\
$\geq 65$ & & \\
Sex & 1.0 & 1.0 \\
Men & $1.34(1.23-1.47)$ & $2.01(1.64-2.47)$ \\
Women & & 1.0 \\
Marital status & 1.0 & $2.35(1.76-3.14)$ \\
Unmarried & $1.92(1.70-2.16)$ & 1.0 \\
Ever-married* & & $1.28(1.06-1.55)$ \\
Area of residence & 1.0 & \\
Rural & $1.23(1.12-1.35)$ & \\
Urban &
\end{tabular}

*Includes married/living with partner and divorced/separated/widower.

$\mathrm{OR}$, odds ratio; $\mathrm{BMI}$, body mass index; $\mathrm{Cl}$, confidence interval.

ried individuals, and individuals living in urban areas.

Estimated crude ORs when the participants were stratified by urban and rural residence are displayed in Table 4. Middle-aged adults (compared to those aged 19-34 years: OR, 1.69-2.69; 95\% CI, 1.25-3.77), women (compared to men: OR, 1.33-2.62; 95\% CI, 1.14-3.89), and ever-married (compared to unmarried: OR, 1.70-3.24; 95\% CI, 1.47-5.55) among both urban and rural residents were more likely to be overweight and obese than their counterparts. However, adults of urban residence had a higher risk of getting overweight and obese than rural adults. For example, the obesity ORs for women living in rural and urban residences were 1.80 and 2.62, respectively, indicating that women in urban residences had 0.82 times greater risk of getting obese than rural women.

\section{DISCUSSION}

Overweight and obesity are well-known health problems in every part of the world, with a prevalence among the adult population significantly varying from $15 \%$ to $60 \%{ }^{2,3}$ During the last two decades, Asian developing countries have become more vulnerable to this serious public health threat. Although there has been a need for updated population-based data on the prevalence of obesity among
Table 4. Estimated crude ORs demonstrating the risk of overweight including obesity $\left(\mathrm{BMI} \geq 25.0 \mathrm{~kg} / \mathrm{m}^{2}\right)$ and obesity alone $\left(\mathrm{BMl} \geq 30.0 \mathrm{~kg} / \mathrm{m}^{2}\right)$, stratified by rural and urban residence

\begin{tabular}{|c|c|c|c|c|}
\hline \multirow[b]{2}{*}{ Characteristics } & \multicolumn{2}{|c|}{ Crude OR (95\% Cl) of rural adult } & \multicolumn{2}{|c|}{ Crude OR (95\% Cl) of urban adult } \\
\hline & $\begin{array}{c}\mathrm{BMl} \\
\geq 25.0 \mathrm{~kg} / \mathrm{m}^{2}\end{array}$ & $\begin{array}{c}\mathrm{BMl} \\
\geq 30.0 \mathrm{~kg} / \mathrm{m}^{2}\end{array}$ & $\begin{array}{c}\mathrm{BMl} \\
\geq 25.0 \mathrm{~kg} / \mathrm{m}^{2}\end{array}$ & $\begin{array}{c}\mathrm{BMl} \\
\geq 30.0 \mathrm{~kg} / \mathrm{m}^{2}\end{array}$ \\
\hline \multicolumn{5}{|l|}{ Age (yr) } \\
\hline $19-34$ & 1.0 & 1.0 & 1.0 & 1.0 \\
\hline $35-44$ & $1.93(1.68-2.21)$ & $2.47(1.86-3.28)$ & $2.08(1.69-2.57)$ & $2.04(1.37-3.06)$ \\
\hline $45-54$ & $2.00(1.72-2.34)$ & $2.43(1.78-3.31)$ & $1.92(1.52-2.42)$ & $1.97(1.27-3.06)$ \\
\hline $55-64$ & $1.69(1.42-2.02)$ & $2.69(1.92-3.77)$ & $2.42(1.81-3.23)$ & $2.13(1.25-3.61)$ \\
\hline$\geq 65$ & $1.29(1.06-1.58)$ & $1.36(0.88-2.13)$ & $0.85(0.58-1.25)$ & $0.80(0.34-1.90)$ \\
\hline \multicolumn{5}{|l|}{ Sex } \\
\hline Men & 1.0 & 1.0 & 1.0 & 1.0 \\
\hline Women & $1.33(1.20-1.49)$ & $1.80(1.41-2.29)$ & $1.35(1.14-1.60)$ & $2.62(1.77-3.89)$ \\
\hline \multicolumn{5}{|l|}{ Marital status } \\
\hline Unmarried & 1.0 & 1.0 & 1.0 & 1.0 \\
\hline Ever-married* & $1.70(1.47-1.96)$ & $2.06(1.47-2.90)$ & $2.63(2.10-3.29)$ & $3.24(1.89-5.55)$ \\
\hline
\end{tabular}

*Includes married/living with partner and divorced/separated/widower. $\mathrm{OR}$, odds ratio; $\mathrm{BMI}$, body mass index; $\mathrm{Cl}$, confidence interval.

adults in Pakistan, few regional studies ${ }^{13-17}$ with adults have identified the escalating rates of overweight and obesity. We therefore established such a kind of study.

Our findings related to overweight (22.8\%) and obesity (5.1\%) are comparable with previously published research on Chinese populations. ${ }^{6,18,19}$ However, these prevalence rates were found to be higher in studies conducted in Canada, ${ }^{20}$ the USA, ${ }^{21}$ Greece, ${ }^{22}$ Korea, ${ }^{23}$ Turkey, ${ }^{24}$ and England, ${ }^{25}$ which confirms the statement that obesity burden varies between countries due to socioeconomic and environmental changes (e.g., climate, diet, physical activity, etc.). Our results are also comparable with the earlier local literature; for example, an urban Karachi survey has shown a 28\% prevalence of overweight/obesity, keeping a BMI of $25.0 \mathrm{~kg} / \mathrm{m}^{2}$ as the cutoff point. ${ }^{17}$ Another study by Khan et al. ${ }^{13}$ reported an obesity prevalence of $4.8 \%$ for Balochistani adults; an obesity rate of $8.0 \%$ was also determined for Peshawari adults. ${ }^{14} \mathrm{~A}$ study reported $25.0 \%$ of adults in Pakistan were either overweight or obese. ${ }^{11}$ However, in this study, $23.0 \mathrm{~kg} / \mathrm{m}^{2}$ was used as the cutoff point for an abnormal BMI. Some regional disparity in the prevalence of overweight (29.0\%-46\%) and obesity (20.8\%-27.85\%) was also seen among Pakistani adults. ${ }^{15,16}$ This disparity may be explained by varying ethnicities, age ranges, and the use of WHO-recommended BMI 
cutoff points for the Asia Pacific Region instead of the international cutoffs for defining obesity.

Our data showed that overweight and obesity were both highest among middle-aged adults (i.e., 35-64 years of age) and lowest in young Pakistani adults (i.e., 19-34 years of age). The rates were consistently higher in women when compared with men across all age-groups. Similar patterns were also observed in an earlier study from Pakistan. ${ }^{11}$ A few studies on Turkish, ${ }^{24}$ Iranian, ${ }^{8}$ and Omani ${ }^{26}$ adults reported the lowest obesity rates for those under 30 years of age and peak obesity between the ages of 30 to 60 years. A study of the Saudi adult population also yielded similar findings. ${ }^{27}$ In agreement with earlier studies, ${ }^{6,8,22,24,26,27}$ Pakistani women had a higher mean BMI than men and occupied more of the obesity burden than did men (e.g., in the overall sample, obesity rates were $6.3 \%$ in women vs. $3.2 \%$ in men). This may be due to the fact that women in Pakistan usually get married in their 20s. Therefore, being confined to the home after marriage and having less physical activity might be the major reason for weight gain. Similar to previous research, ${ }^{13,27,28}$ we observed that ever-married Pakistani adults and adults living in urban areas were more likely to be overweight or obese than those living in rural areas. This is so because in Pakistan, lifestyles are blatantly different in urban and rural areas. Among urban people, a colossal change in nutritional habits and consumption of food has been observed compared to in rural people, and such a sedentary lifestyle may be less focused on attractiveness, leading to more weight gain.

Various published literature has explained that age and other sociodemographic variables such as sex, marital status, and residential area are the significant risk factors for overweight and obesity. ${ }^{8,11,13}$ Parallel to these, our results from logistic regression analysis exhibited that middle-age adults (35-64 years), female sex, married individuals, and individuals living in urban areas had higher risks of excess weight than their counterparts.

The International Obesity Task Force recommended that the 85th and 95th percentiles, corresponding to BMI $25.0 \mathrm{~kg} / \mathrm{m}^{2}$ and $30.0 \mathrm{~kg} / \mathrm{m}^{2}$, respectively, should be used as cutoff points for determining overweight and obesity, respectively, for the adult population. By considering the overall data in our study, a BMI of $25.0 \mathrm{~kg} / \mathrm{m}^{2}$ also corresponds to the 85th percentile in both sexes, and a BMI of $30.0 \mathrm{~kg} / \mathrm{m}^{2}$ corresponds to the 95th percentile in all women, while action level was low among men.

The major strength of this study was that the sampling design and sampling technique for data collection were robust enough to ensure representativeness of the population-based sample and external validity. This is due to the fact that a secondary data set from PPHS-2010 was used. On the other hand, socioeconomic status, diet, and physical activity are also potential risk factors for obesity, but such information was not taken into account in this research, providing a limitation of the study. Moreover, BMI is used for the diagnosis of obesity but cannot provide information about body fat; therefore, we were unable to classify overweight/obesity using body fat percentage as a metric. This fact also adds to the limitations of the present study.

This study reports the high prevalence of overweight and obesity in the Pakistani adult population. Within this population, middleaged (35-64 years) individuals are more likely to become overweight and obese. This risk is especially alarming among Pakistani women, married individuals, and individuals living in urban areas. These findings suggest that there is a need to avoid unhealthy lifestyle habits such as excessive eating and an energy-dense diet, sedentary behavior, and inappropriate sleep duration to improve adult health. Some health promotion programs should also be launched at the national level to decrease the possible epidemic of obesity and obesity-related chronic diseases.

\section{CONFLICTS OF INTEREST}

The authors declare no conflict of interest.

\section{ACKNOWLEDGMENTS}

The authors gratefully acknowledge Dr. Zamir Hussain (National University of Sciences and Technology, Islamabad, Pakistan), who greatly helped us by sharing the data set of the Pakistan Panel Household Survey-2010 in an SPSS file.

\section{AUTHOR CONTRIBUTIONS}

Study concept and design: MA (Muhammad Asif); acquisition of data: MA (Muhammad Asif) and AM; analysis and interpreta- 
tion of data: MA (Muhammad Asif), AM and SA; drafting of the manuscript: MA (Muhammad Asif) and MA (Muhammad Aslam); critical revision of the manuscript: MA (Muhammad Aslam) and SA; statistical analysis: MA (Muhammad Asif) and SA; and study supervision: MA (Muhammad Aslam).

\section{REFERENCES}

1. World Health Organization. Overweight and obesity: an emerging epidemic. In: Nutrition for health and development, editor. Sustainable Development and Healthy Environments (SDE). Geneva: World Health Organization; 2000. p. 18-20.

2. James PT, Leach R, Kalamara E, Shayeghi M. The worldwide obesity epidemic. Obes Res 2001;9 Suppl 4:228S-233S.

3. World Health Organization. Controlling the global obesity epidemic: the challenge [Internet]. Geneva: World Health Organization; 2008 [cited 2019 Nov 20]. Available from: http:// www.who.int/nutrition/topics/obesity/en/

4. World Health Organization. Recommendations for preventing excess weight gain and obesity. In: World Health Organization, editor. Diet, nutrition and the prevention of chronic diseases. Geneva: World Health Organization; 2003. p. 61-71.

5. Ng M, Fleming T, Robinson M, Thomson B, Graetz N, Margono $\mathrm{C}$, et al. Global, regional, and national prevalence of overweight and obesity in children and adults during 1980-2013: a systematic analysis for the Global Burden of Disease Study 2013. Lancet 2014;384:766-81.

6. Jia WP, Xiang KS, Chen L, Lu JX, Wu YM. Epidemiological study on obesity and its comorbidities in urban Chinese older than 20 years of age in Shanghai, China. Obes Rev 2002;3: 157-65.

7. Oğuz A, Temizhan A, Abaci A, Kozan O, Erol C, Ongen Z, et al. Obesity and abdominal obesity: an alarming challenge for cardio-metabolic risk in Turkish adults. Anadolu Kardiyol Derg 2008;8:401-6.

8. Hajian-Tilaki KO, Heidari B. Prevalence of obesity, central obesity and the associated factors in urban population aged 20-70 years, in the north of Iran: a population-based study and regression approach. Obes Rev 2007;8:3-10.

9. Dalton M, Cameron AJ, Zimmet PZ, Shaw JE, Jolley D, Dun- stan DW, et al. Waist circumference, waist-hip ratio and body mass index and their correlation with cardiovascular disease risk factors in Australian adults. J Intern Med 2003;254:555-63. 10. Gallus S, Colombo P, Scarpino V, Zuccaro P, Negri E, Apolone G, et al. Overweight and obesity in Italian adults 2004, and an overview of trends since 1983. Eur J Clin Nutr 2006;60:1174-9.

11.Jafar TH, Chaturvedi N, Pappas G. Prevalence of overweight and obesity and their association with hypertension and diabetes mellitus in an Indo-Asian population. CMAJ 2006;175: 1071-7.

12. Durr-e-Nayab, Arif GM. Pakistan panel household survey: sample size and attrition. Pak Dev Rev 2014;53:223-37.

13. Khan I, Ul-Haq Z, Taj AS, Iqbal AZ, Basharat S, Shah BH. Prevalence and association of obesity with self-reported comorbidity: a cross-sectional study of 1321 adult participants in Lasbela, Balochistan. Biomed Res Int 2017;2017:1076923.

14. Khan A, Afridi AK, Safdar M. Prevalence of obesity in the employees of universities, health and research institutions of $\mathrm{Pe}$ shawar. Pak J Nutr 2003;2:182-88.

15. Amin F, Fatima SS, Islam N, Gilani AH. Prevalence of obesity and overweight, its clinical markers and associated factors in a high risk South-Asian population. BMC Obes 2015;2:16.

16. Aslam M, Saeed A, Pasha, GR, Altaf S. Gender differences of body mass index in adults of Pakistan: a case study of Multan city. Pak J Nutr 2010;9:162-66.

17. Khan FS, Lotia-Farrukh I, Khan AJ, Siddiqui ST, Sajun SZ, Malik AA, et al. The burden of non-communicable disease in transition communities in an Asian megacity: baseline findings from a cohort study in Karachi, Pakistan. PLoS One 2013;8: e56008.

18. Hou X, Jia W, Bao Y, Lu H, Jiang S, Zuo Y, et al. Risk factors for overweight and obesity, and changes in body mass index of Chinese adults in Shanghai. BMC Public Health 2008;8: 389.

19. Wang W, Wang K, Li T. A study on the epidemiological characteristics of obesity in Chinese Adults. Zhonghua Liu Xing Bing Xue Za Zhi 2001;22:129-32.

20. Bélanger-Ducharme F, Tremblay A. Prevalence of obesity in Canada. Obes Rev 2005;6:183-6.

21. Befort CA, Nazir N, Perri MG. Prevalence of obesity among 
adults from rural and urban areas of the United States: findings from NHANES (2005-2008). J Rural Health 2012;28: 392-7.

22. Manios Y, Panagiotakos DB, Pitsavos C, Polychronopoulos E, Stefanadis C. Implication of socio-economic status on the prevalence of overweight and obesity in Greek adults: the ATTICA study. Health Policy 2005;74:224-32.

23. Kim DM, Ahn CW, Nam SY. Prevalence of obesity in Korea. Obes Rev 2005;6:117-21.

24. Yabanci N, Gocgeldi E, Simsek I, Kilic S. Prevalence of obesity, abdominal obesity and the associated factors among a group of Turkish adults. PakJ Med Sci 2010;26:21-5.

25. Rennie KL, Jebb SA. Prevalence of obesity in Great Britain.
Obes Rev 2005;6:11-2.

26. Al-Riyami AA, Afifi MM. Prevalence and correlates of obesity and central obesity among Omani adults. Saudi Med J 2003; 24:641-6.

27. Alsaif MA, Hakim IA, Harris RB, Alduwaihy M, Al-Rubeaan $\mathrm{K}, \mathrm{Al}-\mathrm{Nuaim} \mathrm{AR}$, et al. Prevalence and risk factors of obesity and overweight in adult Saudi population. Nutr Res 2002;22: 1243-52.

28. Dennis B, Aziz K, She L, Faruqui AM, Davis CE, Manolio TA, et al. High rates of obesity and cardiovascular disease risk factors in lower middle class community in Pakistan: the Metroville Health Study. J Pak Med Assoc 2006;56:267-72. 